\title{
Passive Behavior of Ultra-Fine-Grained 1050 Aluminum Alloy Produced by Accumulative Roll Bonding in a Borate Buffer Solution
}

\author{
Arash Fattah-alhosseini ${ }^{1} \cdot$ Seyed Omid Gashti ${ }^{1}$
}

Received: 30 April 2015/Revised: 25 July 2015/Published online: 22 September 2015

(C) The Chinese Society for Metals and Springer-Verlag Berlin Heidelberg 2015

\begin{abstract}
In this study, the effect of the ARB process on the passive behavior of ultra-fine-grained 1050 aluminum alloy in a borate buffer solution ( $\mathrm{pH}$ 6.0) has been investigated. The result of the microhardness tests revealed that the microhardness values increase with an increasing number of ARB cycles. The potentiodynamic polarization plots revealed that the higher number of cycles for the specimens proceeds with the ARB process rather than annealing yield to lower corrosion and passive current densities and more noble corrosion potential values. Moreover, electrochemical impedance spectroscopy measurements showed that increasing the number of ARB cycles offers better conditions for forming the passive films.
\end{abstract}

KEY WORDS: Aluminum; Polarization; Passivation; Electrochemical impedance spectroscopy (EIS)

\section{Introduction}

ARB has been used as a severe plastic deformation (SPD) process for the industrial production of ultra-fine-grained (UFG) sheets with excellent mechanical behaviors. It is found that UFG metals and alloys show better mechanical behavior (such as strength and hardness) than their coarsegrained materials. Recent studies in the fabrication of UFG metals and alloys have focused on the application of large strain or SPD as a method of producing high-strength materials [1-3].

Several SPD methods such as multi-axial forging [4], high-pressure torsion [5], equal channel angular pressing $[6,7]$, and ARB [8-11] have been used for fabrication of high-strength metals and alloys with better mechanical

Available online at http://link.springer.com/journal/40195

Arash Fattah-alhosseini

a.fattah@basu.ac.ir

1 Department of Materials Engineering, Bu-Ali Sina University, Hamedan 65178-38695, Iran behavior. Among these methods, ARB has advantages over other SPD processes. This method, as a high-productivity technique, not required expensive dies and applying large load. Therefore, it is excellent for manufacturing UFG structure sheets [10-13].

Generally, aluminum is a lightweight metal having good corrosion resistance to the atmosphere and many aqueous solutions [14-17]. It is assumed that the passive films formed on aluminum and its alloys are composed of aluminum oxide, which is estimated at about $2-10 \mathrm{~nm}$ in thickness. Indeed, this passive layer forms an efficient barrier against the metal dissolution and undergoes a passivity breakdown under certain conditions [18, 19].

Although the extensive number of works has been reported on the ARB method [1-3, 8-13, 20], but little systematic study has been conducted on the passive behavior of UFG aluminum alloys fabricated by ARB. Generally, it is assumed that the corrosion resistance of UFG metals and alloys is worse than that of its coarse-grained counterpart, due to the higher defect density [11]. It has been reported that the corrosion resistance of UFG Al-Mn alloy produced by ARB in artificial seawater was improved by decreasing the size of $\mathrm{MnAl}_{6}$ particles [12]. Also, it is found that the pitting 
corrosion resistance of 5052 aluminum alloy that was highly deformed by the ARB method is deteriorated. It indicates that the formation of a passive film is difficult by increasing the cold deformations. This could be attributed to the enhanced dislocation density and the number of defects in the material [21].

In this work, the passive behavior of 1050 aluminum alloy produced by ARB was investigated in a borate buffer solution ( $\mathrm{pH}$ 6.0). The potentiodynamic polarization and electrochemical impedance spectroscopy (EIS) were carried out, and also, for evaluation of microstructural behavior, the Vickers microhardness measurements as a function of ARB method were studied by atomic force microscopy (AFM) and scanning electron microscopy (SEM).

\section{Experimental Procedures}

\subsection{ARB Process}

Before any process, 1050 aluminum alloy sheets were cut with the length of $150 \mathrm{~mm}$, the width of $50 \mathrm{~mm}$, and the thickness of $1 \mathrm{~mm}$ and then were annealed in a furnace at $370{ }^{\circ} \mathrm{C}$ for $7200 \mathrm{~s}$. Chemical composition of raw material used in this work is presented in Table 1. In order to produce an acceptable metallurgical bond by the ARB process, it is necessary to remove any contaminations produced on the surface of the strips. All strips were degreased in acetone bath and scratch brushed with stainless steel brush. This is the best method for surface preparation that suggested by a number of authors. The time between surface preparation and rolling was $<120 \mathrm{~s}$.

Figure 1 illustrates the schematic of the ARB process. This process was performed without lubrication, using a laboratory rolling mill with a loading capacity of 20 tons. The roll bonding process was conducted with a reduction of $50 \%$ (equivalent strain of 0.8 per cycle). Then, the rollbonded strip was cut into two strips. The samples with 1,3 , 5 , and 7 cycles were produced for evaluation of passive behavior.

\subsection{Microhardness and AFM Tests}

Before each hardness test, the specimens were consecutively wet-grained to $2000 \mathrm{SiC}$ paper and cleaned by deionized water. Load and indention time of Vickers microhardness measurements were $0.98 \mathrm{~N}$ and $20 \mathrm{~s}$. The

Table 1 Chemical composition (wt\%) of 1050 aluminum alloy

\begin{tabular}{llllllll}
\hline $\mathrm{Mg}$ & $\mathrm{Si}$ & $\mathrm{Fe}$ & $\mathrm{Mn}$ & $\mathrm{Zn}$ & $\mathrm{Ti}$ & $\mathrm{V}$ & $\mathrm{Al}$ \\
\hline 0.02 & 0.04 & 0.35 & 0.01 & 0.01 & 0.01 & 0.01 & $\mathrm{Bal}$. \\
\hline
\end{tabular}

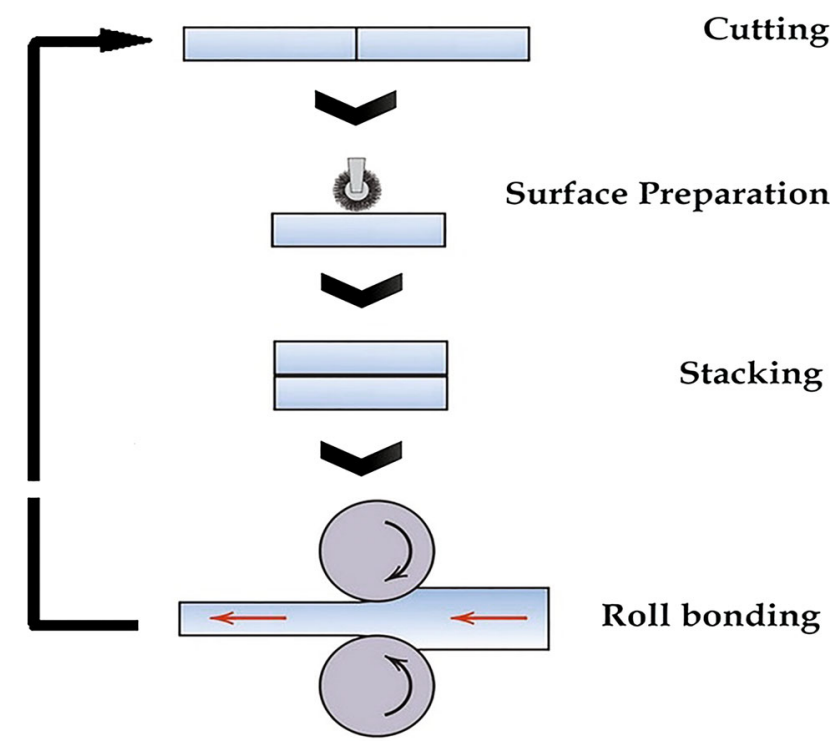

Fig. 1 Schematic illustration of the ARB process

final values were taken as an average of ten measurements. The microhardness of annealed and produced by ARB samples with different cycles was measured and compared. All of tests were done using Buehler (USA) microhardness measurement setup.

AFM measurements were carried out with Auto probe CP Research AFM (Park Scientific Instruments, USA). The cantilever of this microscope was silicon nitride with a tip radius of curvature on the order of nanometers. Data were collected at scan rate of $0.5 \mathrm{~Hz}$ with contact mode, also called static mode. Resolution of the images was $256 \times 256$ pixel. Microstructure of the specimens was analyzed by SEM images that were taken by a JEOL JSM840A microscope.

\subsection{Electrochemical Measurements}

All electrochemical tests were performed in a conventional three-electrode flat cell under aerated conditions by using the $\mu$ Autolab Type III/FRA2 system. The reference and counter electrodes were $\mathrm{Ag} / \mathrm{AgCl}(3 \mathrm{~mol} / \mathrm{L} \mathrm{KCl})$ and platinum rod, respectively. Also, a borate buffer solution with $\mathrm{pH}$ value of $6.0\left(0.3 \mathrm{~mol} / \mathrm{L} \mathrm{H}_{3} \mathrm{BO}_{3}+0.003 \mathrm{~mol} / \mathrm{L}\right.$ $\mathrm{Na}_{2} \mathrm{~B}_{4} \mathrm{O}_{7}$ ) was used as the test solution at room temperature. Prior to electrochemical measurements, all specimens were ground to 2000 grit and cleaned by deionized water. Potentiodynamic polarization curves were measured at a scan rate of $1 \mathrm{mV} / \mathrm{s}$ starting from $-0.25 \mathrm{~V}$ (vs. $E_{\text {corr }}$ ) to 1.0 $V_{\mathrm{Ag} / \mathrm{AgCl}}$. EIS results were obtained at open-circuit potential (OCP) and AC potential with the amplitude of $10 \mathrm{mV}$ and frequency range of $100 \mathrm{kHz}-10 \mathrm{mHz}$. Prior to electrochemical measurements, working electrodes immersed 
at OCP approximately $7200 \mathrm{~s}$ in borate buffer solution to form a steady-state passive film.

The validation of the impedance spectra was performed by checking the linearity condition, i.e., measuring spectra at AC signal amplitudes between 5 and $15 \mathrm{mV}$ (rms) [13]. Each electrochemical test was repeated at least three times. NOVA impedance software was used for data modeling and curve-fitting method.

\section{Results and Discussion}

\subsection{Microhardness and AFM Investigation}

Figure 2 presents the variations in microhardness values of 1050 aluminum alloy specimens (annealed and produced by ARB). It is found that the microhardness values increase with an increasing number of ARB cycles. Moreover, a sharp increase is seen in microhardness $(\sim 46 \%)$ after the first ARB cycle (a strain level of 0.8), whereas mediocre additional increases are observed afterward up to the seven cycles (a strain level of 5.6). The sharp increase at low strains can be attributed to formation of cell wall/subgrain boundaries rather than grain refinement, leading to strain hardening based on the density of dislocations and interactions between them $[8,22]$. These results revealed that the ARB process successfully led to acquiring UFG 1050 aluminum alloy specimens as reported by Rezaei et al. [8] and Shaarbaf and Toroghinejad [22].

The changes of the microstructure with an increasing number of ARB cycles were evaluated by AFM studies for all samples. Figure 3 illustrates the AFM images of the 1, 3,5 , and 7 cycles of the samples produced by the ARB process $(1000 \mathrm{~nm} \times 1000 \mathrm{~nm})$, respectively. Certain grain size decreasing was observed with an increasing number of cycles. Final grain size was reduced to below $200 \mathrm{~nm}$. Also, Fig. 4 presents the SEM micrographs of abovementioned samples. As can be seen, with increasing number of ARB cycles, the grain size of the samples becomes finer and more complicated.

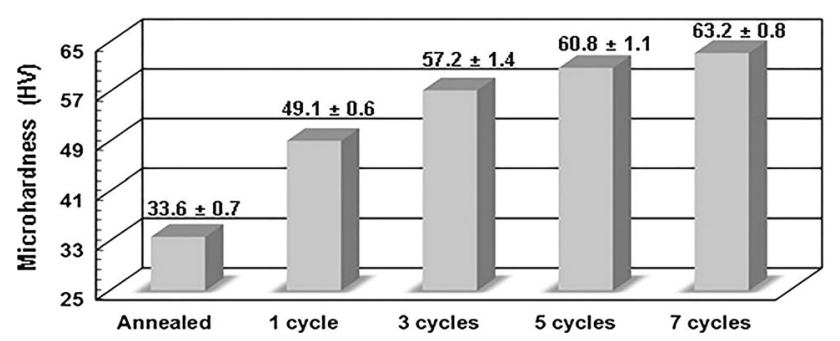

Fig. 2 Variations in microhardness values of 1050 aluminum alloy specimens (annealed and produced by ARB)

\subsection{Potentiodynamic Polarization Measurements}

Figure 5a shows the OCP curves of 1050 aluminum alloy specimens (annealed and produced by ARB) in a borate buffer solution ( $\mathrm{pH}$ 6.0). As can be seen, all curves showed similar trends of increasing the potential toward the positive values. This behavior can be related to the continuous formation of the passive film on the surface [23-25]. Moreover, Fig. 5a displays that after 1800 s, curves show liner behavior and within 7200 s a complete stable condition is achieved to implement the electrochemical tests. After $7200 \mathrm{~s}$, the variation of potential with time is very slight, verifying steady-state conditions dominated.

Reaching a stable OCP of $\mathrm{Al}$ and its alloys in natural solutions in a long period of time has been reported. Liu et al. [23] and Lv et al. [24] have reported that OCP reaches stable conditions after 7200 s. Also, Van Gheem et al. [25] have found that after $8000 \mathrm{~s}$, the stabilization of OCP was reached.

Figure $5 \mathrm{~b}$ shows the potentiodynamic polarization curves of 1050 aluminum alloy specimens (annealed and produced by $\mathrm{ARB}$ ) in a borate buffer solution ( $\mathrm{pH}$ 6.0). According to this figure, all 1050 aluminum alloy specimens produced by ARB exhibit the same curve shapes, where the current changes smoothly and linearly around the rest potential manifesting cathodic and anodic Tafel behavior. Also, no active-passive transition peak can be observed in the anodic curve. As can be seen, except annealed 1050 aluminum alloy specimen, a nearly constant current density was observed in the passive potential region for all specimens.

The variation of the corrosion potential of 1050 aluminum alloy specimens produced by $\mathrm{ARB}$ in a borate buffer solution ( $\mathrm{pH}$ 6.0) is illustrated in Fig. 6. As can be seen, the corrosion potential shifts to more noble values with an increasing number of ARB cycles. Also, the variation of the corrosion and passive current density of 1050 aluminum alloy specimens produced by ARB are shown in Fig. 7. The corrosion current density $\left(i_{\text {corr }}\right)$ was calculated by Tafel extrapolation of the linear part for the cathodic branch back to the corrosion potential with accuracy of more than $95 \%$ for the points more negative to $E_{\text {corr }}$ by $50 \mathrm{mV}[26,27]$. It is released that with an increasing number of ARB cycles, the corrosion and passive current densities decrease. Therefore, it is clear that increasing number of ARB cycles offers better conditions for forming the passive films with higher protection behavior on 1050 aluminum alloy specimens [13].

\subsection{EIS Measurements}

The EIS response of 1050 aluminum alloy specimens (annealed and produced by ARB) in a borate buffer 
(a)

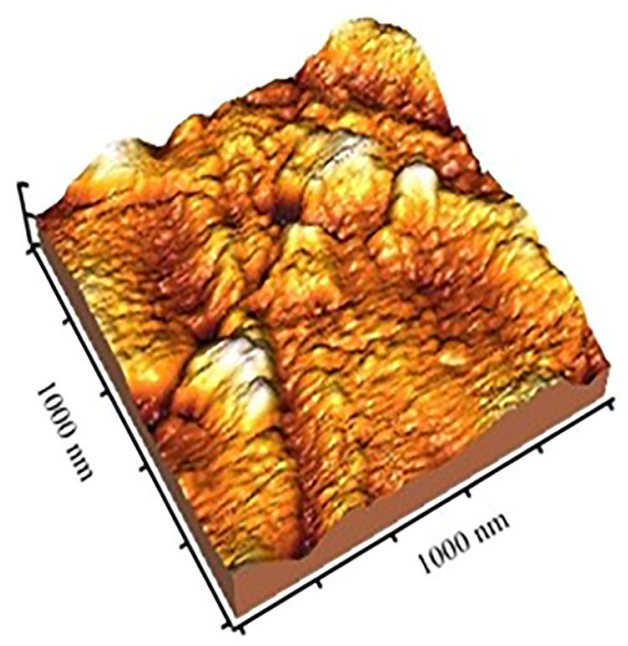

(c)

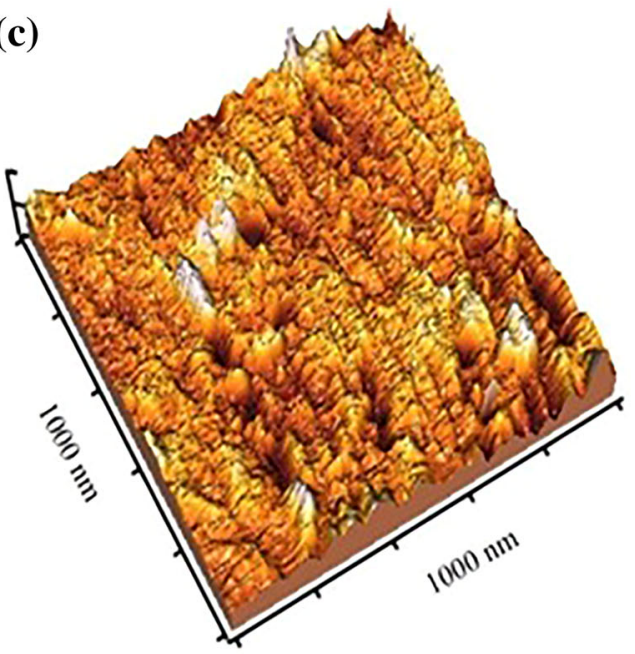

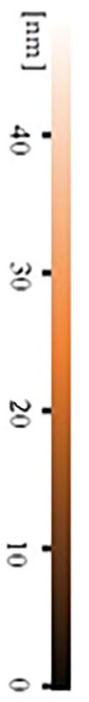

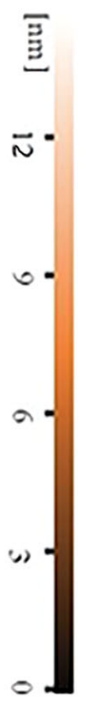

(b)
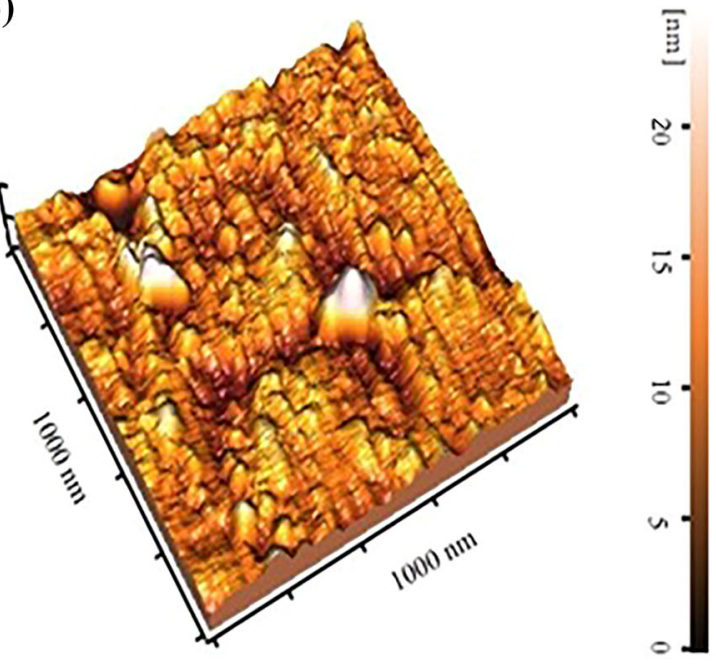

(d)
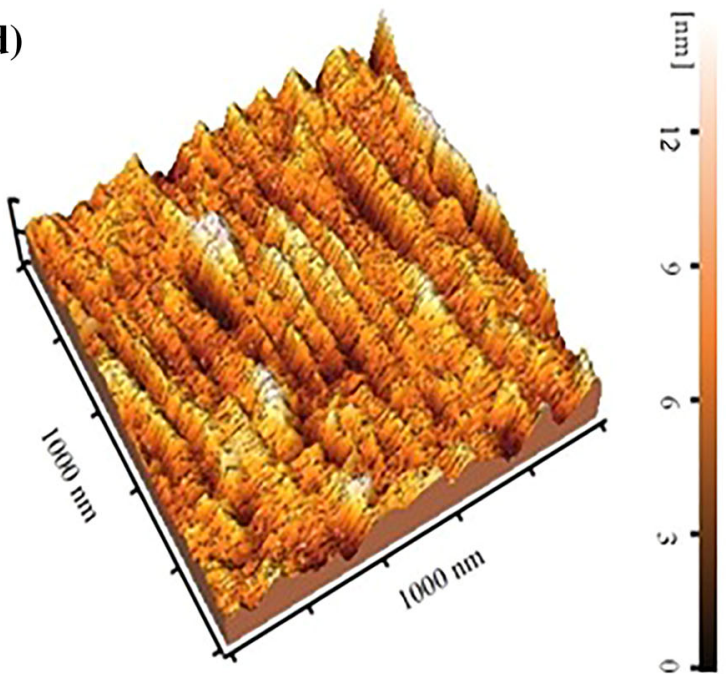

Fig. 3 AFM images of specimens produced by ARB after one $\mathbf{a}$, three $\mathbf{b}$, five $\mathbf{c}$, seven $\mathbf{d}$ cycles

solution ( $\mathrm{pH}$ 6.0) was done at the steady-state corrosion potential, and the results are shown as Nyquist plots in Fig. 8. The Nyquist plots of 1050 aluminum alloy specimens produced by the ARB process include imperfect semicircles. These semicircles show capacitance loop having one time constant. As can be seen, for annealed 1050 aluminum alloy specimen, an inductive loop is observed too. The absence of inductive loops and the presence of the imperfect semicircle with larger diameter for 1050 aluminum alloy specimens produced by the ARB process are related to formation of stable passive film. Also, in Fig. 8, there was an increase in the low-frequency impedance with an increasing number of ARB cycles.

To simulate the measured impedance data of 1050 aluminum alloy specimens produced by the ARB process, the equivalent circuit shown in Fig. 9 (the Randles equivalent circuit) was used. This equivalent circuit is composed of: $R_{\mathrm{S}}$ solution resistance; CPE constant phase element corresponding to the capacitance of the passive film; and $R_{\mathrm{p}}$ passive film resistance (polarization resistance) [11]. The impedance function of a CPE can be represented as Eq. (1) [28]:

$Z_{\mathrm{CPE}}=Y_{0}^{-1}(j \omega)^{-n}$,

where $Y_{0}$ is the CPE constant $\left(\Omega^{-1} \mathrm{~cm}^{-2} \mathrm{~s}^{n}\right), \omega$ is the angular frequency $\left(\mathrm{rad} \mathrm{s}^{-1}\right)$, and $n$ is a parameter related to surface roughness. The factor $n$, defined as a CPE power, always lies between 0.5 and 1 . When $n=1$, the CPE shows ideal capacitor; when $n=0.5$, the CPE displays a Warburg impedance; for $0.5<n<1$, the CPE represents a 

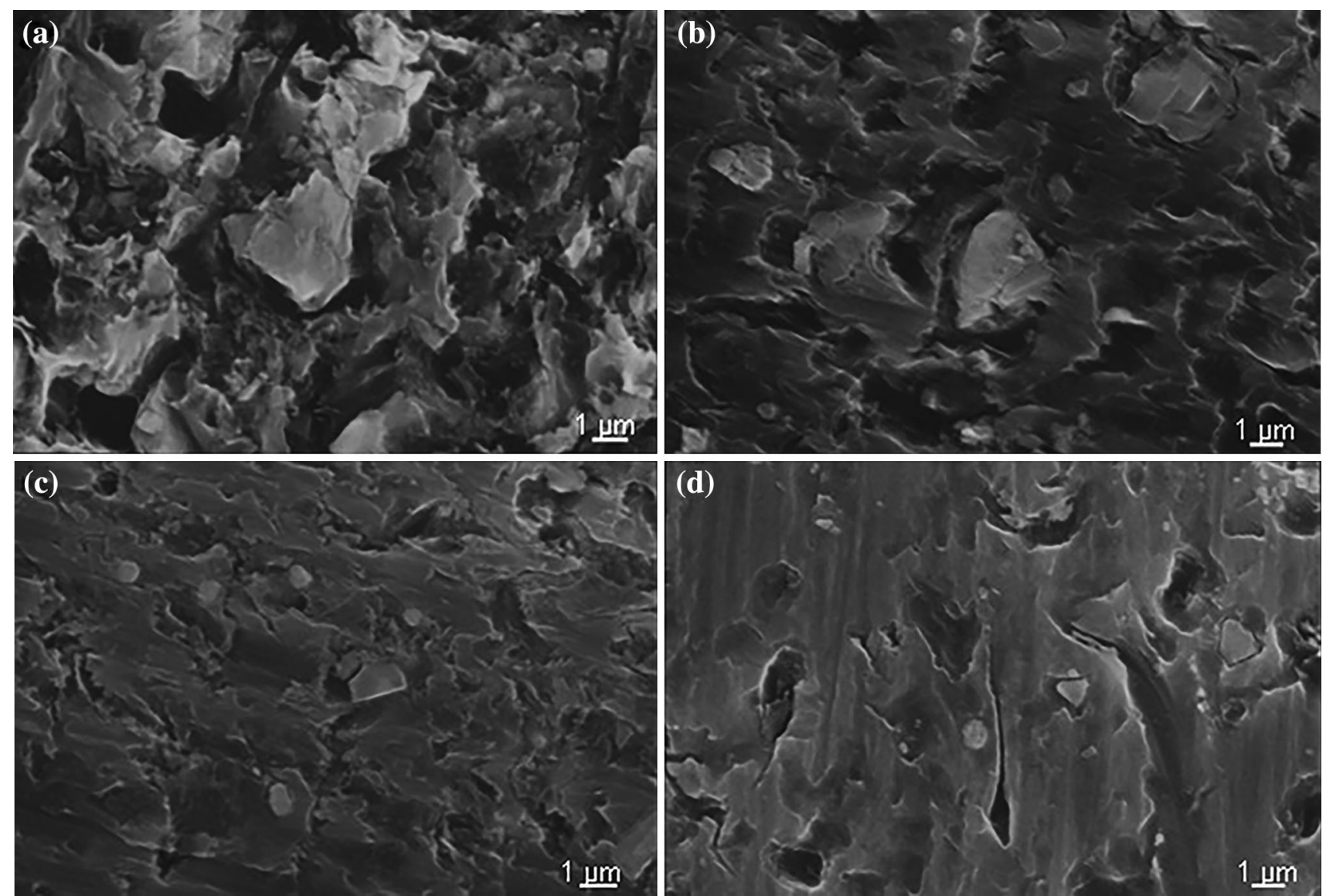

Fig. 4 SEM micrographs of specimens produced by ARB after one $\mathbf{a}$, three $\mathbf{b}$, five $\mathbf{c}$, seven $\mathbf{d}$ cycles in magnification $\times 5000$

distribution of dielectric relaxation times in frequency space [24]. According to Brug et al. [29], the double-layer capacitance $\left(C_{\mathrm{dl}}\right)$ associated with the CPE can therefore be expressed as Eq. (2):

$C_{\mathrm{dl}}=\left[Y_{0} R_{\mathrm{s}}^{(1-n)}\right]^{1 / n}$.

But, for annealed 1050 aluminum alloy specimen, the equivalent circuit shown in Fig. 10 was used to simulate the measured impedance data. In this equivalent circuit, $R$ and $L$ are elements associated with the inductive loop [24].

The variation of the resistance and capacitance of the passive film formed on 1050 aluminum alloy specimens obtained by applying two equivalent circuits (Figs. 9, 10) is illustrated in Fig. 11a, b, respectively. Generally, the diameter of capacitive semicircle was correlated with passive film resistance. An increase in the semicircle diameter indicates an increase in the passive film stability and correlates with thickening or compactness and stability of the passive film [26]. It is observed that the passive film resistance increases with an increasing number of ARB cycles (Fig. 11a). This trend is in good agreement with the variation of the corrosion current density (Fig. 7a), which indicates that the passive film property is improved by increasing number of ARB cycles.

As can be seen in Fig. 11b, capacitance of the passive film decreases with an increasing number of ARB cycles. Based on the equivalent circuits shown in Figs. 9 and 10, the passive film thickness $(d)$ can be determined by Eq. (3) [29-31]:

$d=\varepsilon \varepsilon_{0} A\left(C_{\mathrm{dl}}\right)^{-1}$,

where $C_{\mathrm{dl}}$ is the total capacitance of the passive film, $\varepsilon$ is the dielectric constant of the passive film $(\varepsilon=10$ for aluminum and its alloys [26]), $\varepsilon_{0}$ is the vacuum permittivity $\left(8.854 \times 10^{-14} \mathrm{~F} / \mathrm{cm}\right)$, and $A$ is the area in $\mathrm{cm}^{2}$. Generally, a change in the total capacitance of the passive film $\left(C_{\mathrm{dl}}\right)$ can be used as an indicator for change in the passive film thickness $(d)$. Therefore, the reciprocal capacitance of the passive film $\left(1 / C_{\mathrm{dl}}\right)$ is proportional to its thickness which increases with an increasing number of ARB cycles. Figure 12 illustrates the passive film thickness of 1050 aluminum alloy specimens produced by the ARB process. It is clear that increasing number of ARB cycles gives better conditions for forming the passive films with higher protection behavior, due to the growth of a much thicker passive films. 

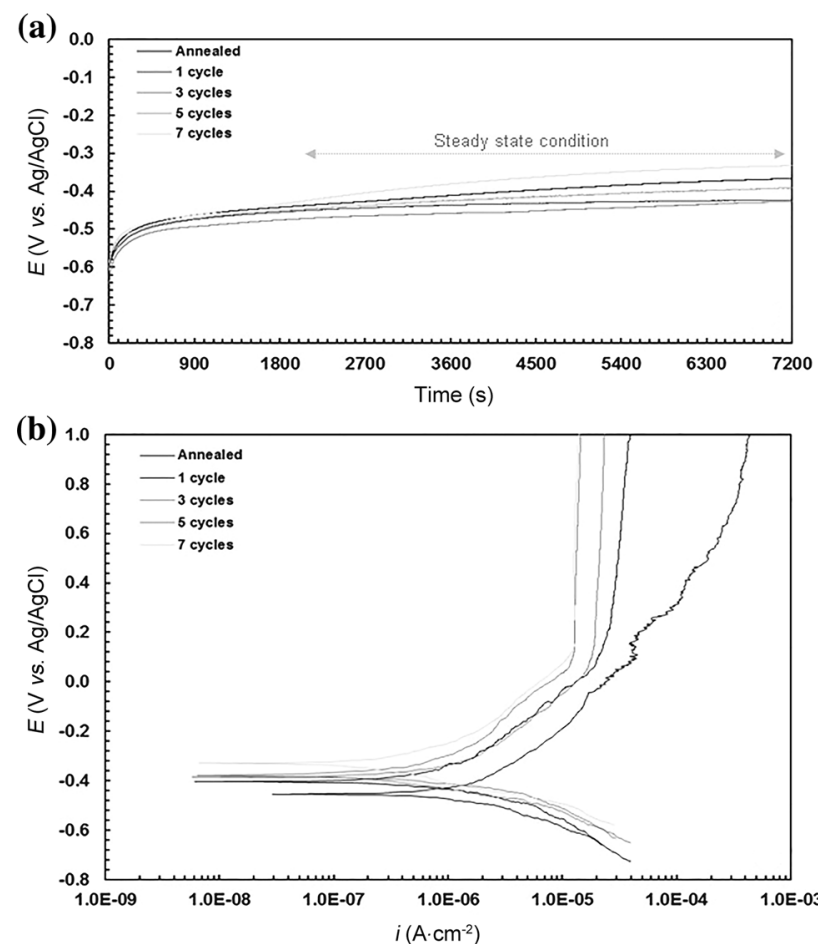

Fig. 5 Open-circuit potential a, potentiodynamic polarization b curves of 1050 aluminum alloy specimens (annealed and produced by $\mathrm{ARB})$ in a borate buffer solution $(\mathrm{pH} 6.0)$

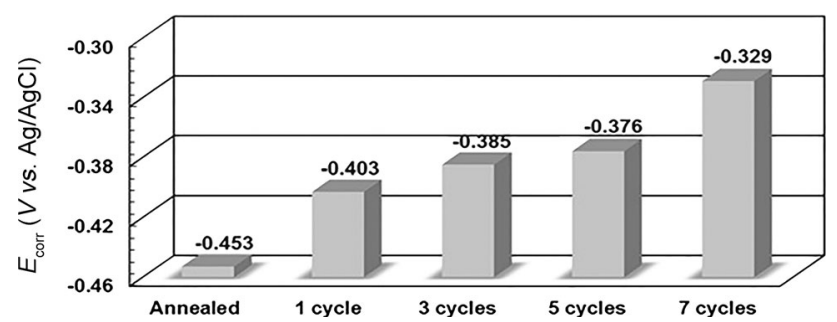

Fig. 6 Variations of the corrosion potential of 1050 aluminum alloy specimens produced by ARB in a borate buffer solution ( $\mathrm{pH}$ 6.0)

Due to strain hardening by dislocations and grain refinement, the ARB method led to increase in the hardness of materials (according to Fig. 2). Therefore, after applying this process, dislocation density and fraction of the grain boundary of bulk material rise up [32]. Indeed, the ARB process led to acquiring UFG metals and alloys with a large fraction of grain boundaries and high internal energy. Moreover, on the side of the grain boundaries and inside some grains, the dislocation density and residual stress are high [11]. On the other hand, UFG structure with nonequilibrium grain boundaries and high residual stresses inside the grains and large fraction of defects are the preferential sites for nucleation of passive film [12]. In this manner, high residual stress prepares the UFG metals and alloys more nuclei to form denser passive film, improving
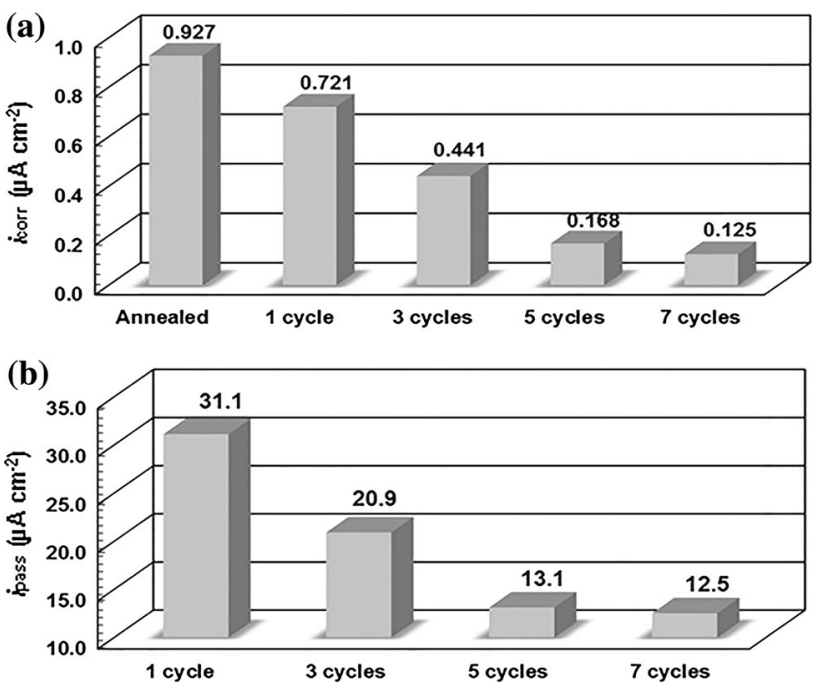

Fig. 7 Variations of the corrosion a, passive b current density of 1050 aluminum alloy specimens produced by ARB in a borate buffer solution ( $\mathrm{pH}$ 6.0)

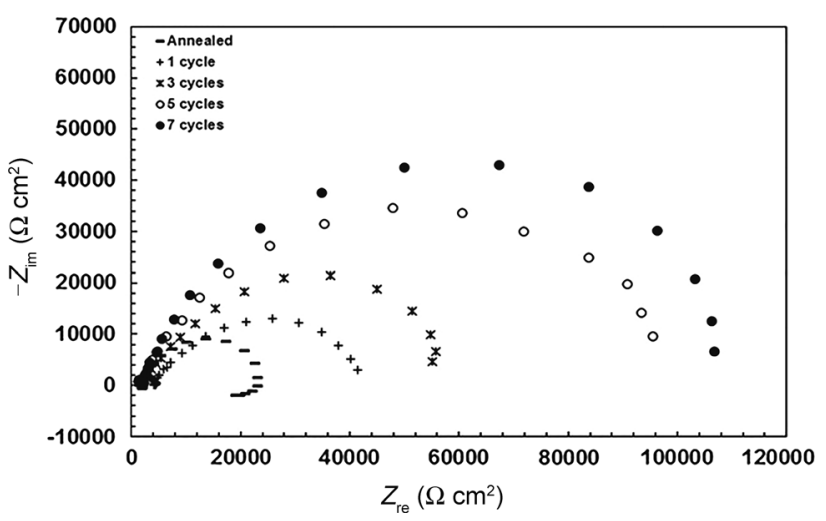

Fig. 8 Effect of number of ARB cycles on the Nyquist plots of 1050 aluminum alloy in a borate buffer solution $(\mathrm{pH} 6.0)$

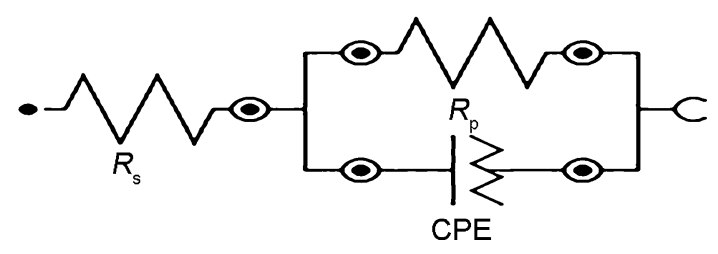

Fig. 9 Best equivalent circuit used to model the experimental EIS data of 1050 aluminum alloy specimens produced by ARB

the corrosion resistance. Also, the formation of UFG structures provides that the passive film grows more rapidly [33-35]. As a result, the oxide film which forms on such high-level internal energy and defectful substrate have more defective structure, and with an increasing number of ARB cycles, its thickness is higher and its passive behavior is better [21]. 


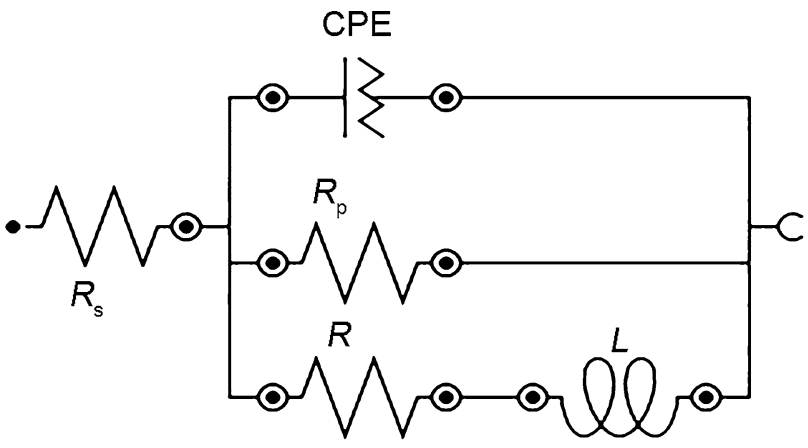

Fig. 10 Best equivalent circuit used to model the experimental EIS data of annealed 1050 aluminum alloy specimen
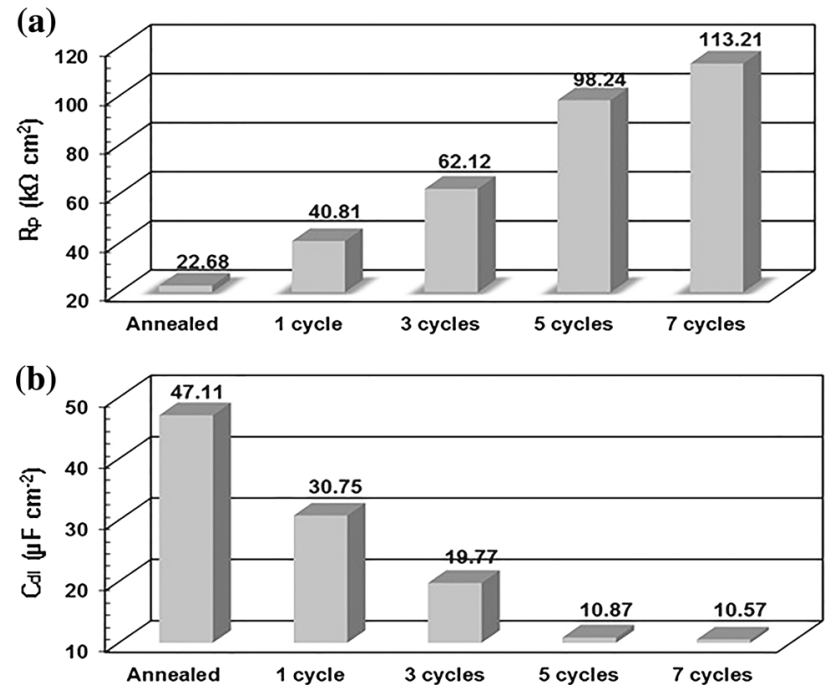

Fig. 11 Effect of number of ARB cycles on the resistance a, capacitance $\mathbf{b}$ of the passive films formed on 1050 aluminum alloy in a borate buffer solution ( $\mathrm{pH} 6.0$ )

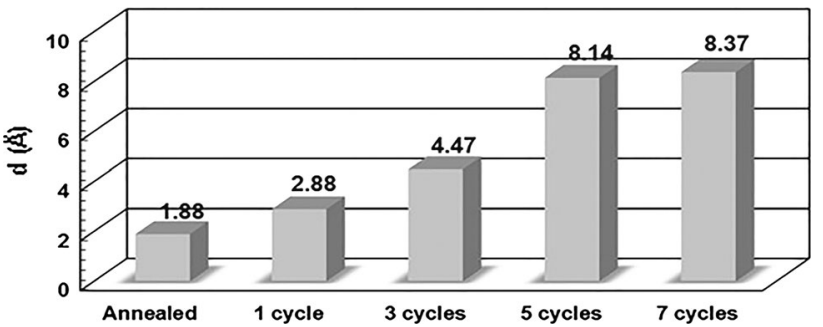

Fig. 12 Effect of number of ARB cycles on the thickness of the passive films formed on 1050 aluminum alloy in a borate buffer solution $(\mathrm{pH} 6.0)$

\section{Conclusions}

1. The microhardness tests revealed that microhardness values increase with an increasing number of ARB cycles.
2. Results of AFM tests and SEM micrographs displayed that with increasing in cycle number of ARB, the grain size of the specimens decreases.

3. The potentiodynamic polarization plots showed that as a result of ARB, the passive behavior of the specimens increases, compared to the annealing aluminum plate.

4. These plots revealed that the higher number of cycles for the specimens proceeds with the ARB process rather than annealing yield to lower corrosion and passive current densities and more noble corrosion potential values.

5. EIS results showed that the passive film resistance increases with an increasing number of ARB cycles

6. Also, EIS results showed that the thickness of the passive film increases with an increasing number of ARB cycles.

7. Finally the results indicated that increasing number of ARB cycles gives better conditions for forming the passive films with higher protection behavior, due to the growth of a much thicker passive films.

\section{References}

[1] M. Raei, M.R. Toroghinejad, R. Jamaati, J.A. Szpunar, Mater. Sci. Eng. A 527, 7068 (2010)

[2] S. Pasebani, M.R. Toroghinejad, Mater. Sci. Eng. A 527, 491 (2010)

[3] S. Pasebani, M.R. Toroghinejad, M. Hosseini, J. Szpunar, Mater. Sci. Eng. A 527, 2050 (2010)

[4] M. Montazeri-Pour, M.H. Parsa, H.R. Jafarian, S. Taieban, Mater. Sci. Eng. A 639, 705 (2015)

[5] X. Wang, M. Nie, C.T. Wang, S.C. Wang, N. Gao, Mater. Des. 83, 193 (2015)

[6] F. Salimyanfard, M.R. Toroghinejad, F. Ashrafizadeh, M. Hoseini, J.A. Szpunar, Mater. Des. 44, 374 (2013)

[7] Z.M. Zhang, C.J. Xu, J.C. Wang, H.Z. Liu, Acta Metall. Sin. (Engl. Lett.) 19, 223 (2006)

[8] M.R. Rezaei, M.R. Toroghinejad, F. Ashrafizadeh, J. Mater. Proc. Technol. 211, 1184 (2011)

[9] R. Jamaati, M.R. Toroghinejad, A. Najafizadeh, Mater. Sci. Eng. A 527, 2720 (2010)

[10] R. Jamaati, M.R. Toroghinejad, A. Najafizadeh, Mater. Sci. Eng., A 527, 3857 (2010)

[11] M. Kadkhodaee, M. Babaiee, H.D. Manesh, M. Pakshir, B. Hashemi, J. Alloys Compd. 576, 66 (2013)

[12] W. Wei, K.X. Wei, Q.B. Du, Mater. Sci. Eng. A 454, 536 (2007)

[13] A. Fattah-alhosseini, O. Imantalab, J. Alloys Comp. 632, 48 (2015)

[14] K.C. Emregul, A.A. Aksut, Corros. Sci. 42, 2051 (2000)

[15] S.S.A. Rehim, H.H. Hassan, M.A. Amin, Appl. Surf. Sci. 187, 279 (2002)

[16] K. Ishii, R. Ozaki, K. Kaneko, H. Fukushima, M. Masuda, Corros. Sci. 49, 2581 (2007)

[17] W.R. Osório, L.C. Peixoto, L.R. Garcia, A. Garcia, Acta Metall. Sin. (Engl. Lett.) 22, 241 (2009)

[18] F. Rosalbino, S. Delsante, G. Borzone, E. Angelini, Corros. Sci. 52, 322 (2010) 
[19] B. Zhang, Y. Li, F. Wang, Corros. Sci. 49, 2071 (2007)

[20] R. Jamaati, M.R. Toroghinejad, H. Edris, Mater. Sci. Eng. A 578, 191 (2013)

[21] M.F. Naeini, M.H. Shariat, M. Eizadjou, J. Alloys Comp. 509, 4696 (2011)

[22] M. Shaarbaf, M.R. Toroghinejad, Mater. Sci. Eng. A 473, 28 (2008)

[23] Y. Liu, G.Z. Meng, Y.F. Cheng, Electrochim. Acta 54, 4155 (2009)

[24] J.L. Lv, H.Y. Luo, Surf. Coat. Technol. 235, 513 (2013)

[25] E. Van Gheem, J. Vereecken, C. Le Pen, J. Appl. Electrochem. 32, 1193 (2002)

[26] S.O. Gashti, A. Fattah-alhosseini, Anal. Bioanal. Electrochem. 6, 535 (2014)

[27] O. Imantalab, A. Fattah-alhosseini, J. Mater. Eng. Perform. 24, 2579 (2015)
[28] B. Hirschorn, M.E. Orazem, B. Tribollet, V. Vivier, I. Frateur, M. Musiani, Electrochim. Acta 55, 6218 (2010)

[29] G.J. Brug, A.L.G. Van den Eeden, M. Sluyters-Rehbach, J.H. Sluyters, J. Electroanal. Chem. 176, 275 (1984)

[30] J.J. Gray, B.S. El Dasher, C.A. Orme, Surf. Sci. 600, 2488 (2006)

[31] J.J. Gray, C.A. Orme, Electrochim. Acta 52, 2370 (2007)

[32] M.R. Toroghinejad, R. Jamaati, J. Dutkiewicz, J.A. Szpunar, Mater. Des. 51, 274 (2013)

[33] K.T. Aust, U. Erb, G. Palumbo, Mater. Sci. Eng. A 176, 329 (1994)

[34] M. Eizadjou, H.D. Manesh, K. Janghorban, Mater. Des. 29, 909 (2008)

[35] M. Eizadjou, H.D. Manesh, K. Janghorban, Mater. Des. 30, 4156 (2009) 